\title{
Experimental Analysis on Properties of Concrete with Partial Replacement of Cement with Stone Dust
}

\author{
Priyanka Raj ${ }^{1}$, Md.Shafique Alam ${ }^{2}$ \\ 1, 2 Department of Civil Engineering, Cambridge Institute of Technology, Tatisilwai, Ranchi \\ Corresponding Author: Priyanka Raj
}

\begin{abstract}
Due to the auspicious attribute of concrete such as durability, availability, versatility, good compressive strength, it is one of the most commonly used Building materials throughout the world. The demand for infrastructural facilities is increasing day by day which creates a tremendous pressure on concrete as well as on natural aggregates. Apparently it becomes unavoidable to look for alternative materials. On the other hand, disposal of stone dust generated from stone crusher is becoming a problem. Substituting cement by stone dust will serve the waste management as well as the alternative material in concrete. Here in the the present study stone dust is used for partial replacement of cement in concrete by studying the strength property of concrete. The aim of this experiment is to find the maximum content of stone dust by partial replacement of cement. The percentage of stone dust by partial replacement of cement in concrete are $(0 \%, 5 \%, 10 \%, 15 \%$, and $20 \%)$ was studied; on M20 grade of concrete. The result of this present investigation indicates that the replacement of $10 \%$ of cement with waste stone powder attains maximum compressive, flexural and tensile strength. The optimum percentage for replacement of stone powder with cement and it is almost $10 \%$ cement for both cubes beam and cylinders and it also minimize the costs for construction with usage of stone powder which is freely or cheaply available more importantly.
\end{abstract}

Keywords:-Stone dust, partial replacement, compressive strength, flexural \& tensile strength.

\section{INTRODUCTION}

Concrete is a composite material made from binding material like cement, coarse $\&$ fine aggregate and water. It is a versatile construction material due to its reasonable cost \& easy availability of its constituents. It is the most widely used construction material in civil engineering industry because of its high structural strength \& stability \& the most popular building material in the world. Leaving waste materials into environment directly results to damage of natural climatic conditions, hence use of waste materials is made at most importance in present study. Stone dust a waste obtained from crushing of stones used as partial replacement to cement. Concrete is known to be the most wide spread structural material due to its quality to shape up in various geometrical configuration. As we are growing rapidly day to day like a velocity of bullet but in the way of that growing we have left different kinds of waste materials which affect our environment directly or indirectly. After the thought comes for sustainable development, researchers are working on that and use different waste materials into account. This paper also a part of that and summarized the behaviour of concrete involving partial replacement of cement by stone dust as $0 \%$,
$5 \%, 10 \%, 15 \% \& 20 \%$ by weight of which may help to reduce the disposal problems of stone dust \& check the strength and properties of concrete.

\section{LITERATURE REVIEW}

A.M. Mustafa Al Bakri1 et al. [7]They have investigated the strength of concrete with ceramic waste as replacement of coarse aggregate in concrete. The sources of ceramic waste are obtained from the industrial in Malaysia. Presently, in ceramics industries the production goes as waste, which is not undergoing the recycle process yet. The potential of recycled ceramic waste as a substitute for coarse aggregates in concrete has been investigated. The recycle ceramic waste as aggregate was used. Concrete mixes with a 28 days characteristic strength of $20 \mathrm{MPa}$ had prepared using water/cement ratio of $0.4,0.5$ and 0.7 . The strength development of the concrete mixes containing recycled ceramic waste aggregates was compared to that of conventional concrete. They have resulted that the concrete mixes containing recycled ceramic waste aggregates achieve strength levels between 80 to $95 \%$ compared to theconventional concrete. They have concluded that 
ceramic waste can be effectively replaced partially by cement in concrete.

Amitkumar D. Raval et al.[9] They have studied about the (OPC) cement has been replaced by ceramic waste powder accordingly in the range of $0 \%, 10 \%, 20 \%, 30 \% 40 \%$, \& $50 \%$ by weight for M25 grade concrete. The wastes employed came from ceramic industry which had been deemed unfit for sale due to a variety of reasons, including dimensional or mechanical defects, or defects in the firing process. They have resulted demonstrate that the use ceramic masonry rubble as active addition endows cement with positive characteristics as major mechanical strength and the economic advantages. Reuse of this kind of waste has advantages economic and environmental, reduction in the number of natural spaces employed as refuse dumps. Indirectly, all the above contributes to a better quality of life for citizens and to introduce the concept of sustainability in the construction sector.

Lakshmi.R and Nagan.S [10] They have stated about the use of materials like electronic waste not only helps in getting them utilized in cement, concrete and other construction materials, it helps in reducing the cost of cement and concrete manufacturing, but alsohas numerous indirect benefits such as reduction in landfill cost, saving in energy, and protecting the environment from possible pollution effects. The Electronic waste, shortened as Electronic waste, consists of discarded old computers, TVs, refrigerators, radios basically any electrical or electronic appliance that has reached its end-of-life. Labors have been made in the concrete industry to use non-biodegradable components of Electronic waste as a partial replacement of the coarse or fine aggregates. They have also studies about experimental study is made on the utilization of Electronic waste particles as coarse aggregates in concrete with a percentage replacement ranging from $0 \%$ to $30 \%$ on the strength criteria of M20 Concrete. Compressive strength, Tensile strength and Flexural strength of Concrete with and without Electronic waste as aggregates had observed which exhibits a good strength gain. Ultrasonic tests on strength properties had executed and the feasibility of utilizing Electronic plastic particles as partial replacement of coarse aggregate has been presented.

C Freeda Christy and D Tensing[11]The have investigated about the results of the cement mortar of mix proportion 1:3,1:4.5 and 1:6 cement mortar in which cement is partially replaced with Class-F fly ash as $0 \%, 10 \%, 20 \%, 25 \%$ and $30 \%$ by weight of cement. Richer the mix, higher the compressive strength has been obtained even with partial replacement of fly ash with cement. They have studies on the test results indicate the important improvement in the strength properties of mortar with fly ash as partial replacement with cement \& fine aggregate in the cement mortar 1:6.

\section{MATERIALS USED:-}

CEMENT cement is a fine powder, which when mixed with water and allowed to set and harden, is capable of uniting fragments or masses of solid matter together to produce a mechanically strong material. Ordinary Portland cement of grade 43 was used for preparation of concrete mix. The quality of cement was checked through various tests and was compared with the specifications given in IS 81121989 for ordinary Portland cement.

STONE DUST Stone dust is collected from local stone crushing units of Ranchi. It was initially dry in condition when collected and was sieved by IS: 90 micron sieve before mixing in concrete. Specific gravity observed for quarry dust is 2.5 .

\section{Fine Aggregate}

Sand is a naturally occurring granular material composed of finely divided rock and mineral particles. It is defined by size, being finer than gravel and coarser than silt.

\section{Coarse Aggregate}

Coarser aggregate is a kind of aggregates which retain on $4.75 \mathrm{~mm}$ IS sieve, but inThe importance of using the right type and quality of aggregates cannot be overemphasized. The fine and coarse aggregates generally occupy $60 \%$ to $75 \%$ of the concrete volume (70\% to $85 \%$ by mass) and strongly influence the concrete's freshly mixed and hardened proper ties, mixture proportions, and economy. Fine aggregates generally consist of natural sand or crushed stone with most particles smaller than $5 \mathrm{~mm}$ (0.2 in.). Coarse aggregates is a combination of gravels or crushed stone with particles predominantly larger than $5 \mathrm{~mm}$ (0.2 in.) and generally between $9.5 \mathrm{~mm}$ and $37.5 \mathrm{~mm}$ natural aggregate deposits, called pit-run gravel, consist of gravel and sand that can be readily used in concrete after minimal processing. Natural gravel and sand are usually dug or dredged from a pit, river, lake, or seabed. I this experimental analysis I have used coarse aggregate available from nearby crusher. The aggregate was cleaned from all impurities and dust. The coarse aggregate passing through $10 \mathrm{~mm}$ sieve and retained on 600 micron sieve are mixed in proportion of 60:40 percent.

\section{Water \\ Potable tap water available in laboratory was used for mixing and curing of Concrete.}

\section{Concrete Mix Design}

In the present study, M20 grade with nominal mix as per IS 456-2000 was used. The 
concrete mix proportion (cement: fine aggregate: coarse Aggregate) is 1: 1.5: 3 .

\section{Casting and Testing Detail:-}

Total number 30 cubes 30 beam and 15 cylinders Were casted. Stone dust was added in concrete in step of $5 \%(0 \%, 5 \%, 10 \%, 15 \%$, And $20 \%$ ). For each percent of stone dust replacing Cement, 15 cubes \& 15 beams Were casted for 7 days and 15 cubes, 15 beams \&15 cylinders are casted for 28 Days. Final strength of cube beam \& cylinder were gain after 7 day \& 28 days curing. Compression testing machine is used for testing the compressive strength of cube, Flexural Strength of beam and split tensile strength of cylinder.

\section{TESTS}

\section{Cement:-}

Initial setting time of cement:-100 min

Final setting time of cement:-232 min

Specific gravity of cement:-3.15

Consistency of cement:-34\%

Soundness of cement:-9 mm

Stone dust:-

Specific gravity of stone dust:-2.5

Fine Aggregate:-

Fineness modulus:-3.29

Coarse aggregate:-

Fineness modulus:-7.10

\section{RESULT AND DISCUSSION}

After completion of various tests on cement and concrete I have found different results for 7 and 28 days in terms of compressive, flexural and split strength of concrete.

Ratio = 1: 1.88: 2.86

\subsection{Quantity of materials required for cube}

Volume of cube $=(0.15 \times 0.15 \times 0.15) \mathrm{X}$

$6=20.25 \times 10^{-3} \mathrm{~m}^{3}$

Mass of concrete $=$ Density X Volume $=2400 \mathrm{X}$

$20.25 \times 10^{-3}=48.6 \mathrm{Kg}$.

Add $20 \%$ extra dry material $=48.6 \times 1.2=58.32 \mathrm{Kg}$.

\subsubsection{For normal concrete}

Amount of cement $=\frac{1}{5.74} \times 58.32=10.16 \mathrm{Kg}$.

Amount of fine aggregate $=\frac{1.67}{5.74} \times 58.32=16.96 \mathrm{Kg}$.

Amount of coarse aggregate $=\frac{2.99}{5.74} \times 58.32=30.37$ $\mathrm{Kg}$.
Water content $=0.5 \times 10.30=5080 \mathrm{ml}$

\subsubsection{For 5\% replacement}

$$
\mathrm{SDP}=\frac{5}{100} \times 10.16=508 \mathrm{~g}
$$

Cement $=10.16-0.508=9.652 \mathrm{~kg}$

Fine aggregate $=16.96 \mathrm{~kg}$

Coarse aggregate $=30.37 \mathrm{~kg}$

\subsubsection{For $10 \%$ replacement}

$$
\begin{aligned}
& \quad \frac{10}{100} \text { X } 10.16=1.016 \mathrm{Kg} \\
& \text { Cement }=10.16-0.508=9.652 \mathrm{~kg} \\
& \text { Fine aggregate }=16.96 \mathrm{~kg} \\
& \text { Coarse aggregate }=30.37 \mathrm{~kg}
\end{aligned}
$$

\subsubsection{For $15 \%$ replacement}

$$
\begin{aligned}
& \text { SDP }=\frac{15}{100} \text { X } 10.16=1.524 \mathrm{~kg} \\
& \text { Cement }=10.16-1.524=8.636 \mathrm{~kg} \\
& \text { Fine aggregate }=16.96 \mathrm{~kg} \\
& \text { Coarse aggregate }=30.37 \mathrm{~kg}
\end{aligned}
$$

\subsubsection{For $20 \%$ replacement}

$$
\mathrm{SDP}=\frac{\frac{20}{100}}{\mathrm{C}} \mathrm{X} 10.16=2.032 \mathrm{~kg}
$$

Cement $=10.16-2.032=7.968 \mathrm{~kg}$

Fine aggregate $=16.96 \mathrm{~kg}$ Coarse aggregate $=30.37 \mathrm{~kg}$

5.2. Quantity of materials required for cylinder Volume of cube $=($ Area of circle $X$ height $)$ X $6=$

$$
\frac{\pi \times 100^{2}}{4} \times 220 \times 6==10.36 \times 10^{-3} \mathrm{~m}^{3}
$$

Mass of concrete $=$ Density X Volume $=2400 \mathrm{X}$ $10.36 \times 10^{-3} \mathrm{~m}^{3}==24.864 \mathrm{~kg}$

Add $20 \%$ extra dry material $=24.864$ X $1.2=29.83$ $\mathrm{Kg}$

\subsubsection{For normal concrete}

Amount of cement $=\frac{1}{5.74} \times 29.83=5.19 \mathrm{Kg}$.

Amount of fine aggregate $=\frac{1.67}{5.74} \times 29.83=8.67 \mathrm{Kg}$.

Amount of coarse aggregate $=$
Kg. 
Water content $=0.5 \times 5.19=2595 \mathrm{ml}$

\subsubsection{For 5\% replacement}

$$
\begin{aligned}
& \mathrm{SDP}=\frac{5}{100} \times 5.19=259.5 \mathrm{~g} \\
& \text { Cement }=5.19-0.259=4.931 \mathrm{~kg} \\
& \text { Fine aggregate }=8.67 \mathrm{~kg}
\end{aligned}
$$

Coarse aggregate $=15.53 \mathrm{~kg}$

\subsubsection{For $10 \%$ replacement}

$$
\mathrm{SDP}=\frac{10}{100} \text { X } 5.19=519 \mathrm{~g}
$$

Cement $=5.19-0.519=4.671 \mathrm{~kg}$

Fine aggregate $=8.67 \mathrm{~kg}$

Coarse aggregate $=15.53 \mathrm{~kg}$

\subsubsection{For $15 \%$ replacement}

$\mathrm{SDP}=\frac{15}{100} \times 5.19=778.5 \mathrm{~g}$

Cement $=5.19-0.778=4.412 \mathrm{~kg}$

Fine aggregate $=8.67 \mathrm{~kg}$

Coarse aggregate $=15.53 \mathrm{~kg}$

5.2.5. For $20 \%$ replacement

$$
\mathrm{SDP}=\frac{20}{100} \text { X } 5.19=1.038 \mathrm{~kg}
$$

Cement $=5.19-1.038=4.152 \mathrm{~kg}$

Fine aggregate $=8.67 \mathrm{~kg}$

Coarse aggregate $=15.53 \mathrm{~kg}$

\section{GRAPH NO.6.1 \\ LINE GRAPH:- \\ GRAPH NO. 6.2}

\section{GRAPHS}

6.2.1 Combined result of Strength of Plain

\begin{tabular}{|c|c|c|c|c|c|}
\hline \multicolumn{5}{|c|}{ 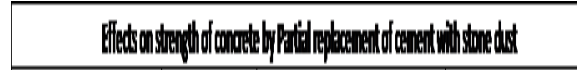 } & \multirow[b]{2}{*}{ Gidetitit } \\
\hline \multicolumn{2}{|c|}{ thashentit } & \multirow[b]{2}{*}{ Mophentik } & \multirow[b]{2}{*}{ 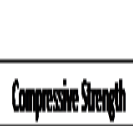 } & \multirow[b]{2}{*}{ 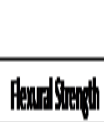 } & \\
\hline Illo & Siptote & & & & 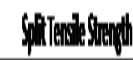 \\
\hline 1 & $\mathbb{A}-\mathrm{C}$ & 1 & 189 & 你 & ith \\
\hline 1 & $A-(X)$ & j & 2601 & 6 & 3 \\
\hline 4 & $H-(X)$ & $\|$ & 999 & 67 & 1] \\
\hline 5 & $\|-(x) \mid$ & 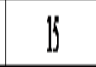 & 21106 & al & 1.51 \\
\hline 6 & $A-(X)$ & ע & 1916 & 58 & 25 \\
\hline
\end{tabular}
Concrete after 28 Days

Strength of Concrete after 28 days curing been done and found different results for compressive and flexural strength

\section{BAR GRAPH \\ GRAPH NO.6.3 \\ GRAPH NO. 6.4}

\section{CONCLUSION}

Today we live in the world full of development and enthusiastic for still more comfort and facilities. This leads to innovations and revolutions in each and every field, but on contrary it has negative impact on environment as resources get depleted and pollution to different natural sources are occurred. So after studying all these research paper we concluded that if we can reduce or reuse some material in field of concrete production which is at its top now-a-days then it largely impact environment and leads to pollution free and soothing surrounding. Thus as concluded from above literature review we can research further more in direction of partially replacing cement, sand and aggregate up to most optimum level we can by reusing or introducing waste material as its option. From studying all these research paper it is clear that positive and favorable results are obtained if further research work and study is carried out in this field. And by using locally available wastes like Stone dust, glass waste, marble dust powder, ceramic waste, quarry, GGBS, Fly ash, etc. as partial substitution at place of concrete ingredients, it may prove more economical than traditional concrete and question of damping of such waste produced by different industries is also get solved. Ultimate goal is to produce economical and eco-friendly concrete with all desired properties and strength which one obtains by regular concrete ingredients. As I have got the result after completion of this project that if we Partial replaced the OPC grade 43 by $10 \%$ of stone dust we can get the optimum result in terms of greater compressive strength and split tensile strength after 7 and 28 days.

\section{REFERENCES}

[1] Concrete Technology- M.S. Shetty

[2] Design of Concrete Mixes-N. Krishna Raju. 
[3] A.V.S.Sai. Kumar, Krishna Rao B, A Study on Strength of Concrete With PartialReplacement Of Cement With Quarry DustAnd Metakaolin, International Journal of Innovative Research in Science, Engineering and Technology, ISSN: 23198753

[4] S. Sureshchandra, G. Sarangapani, and B. G. Naresh Kumar, Experimental Investigation on the Effect of Replacementof Sand by Quarry Dust in Hollow Concrete Block for Different Mix Proportions, International Journal of Environmental Science and Development, Vol. 5, No. 1, February 2014

[5] K N NARASIMHA PRASAD, GANESH N, RAKESH S, Effect of Stone Dust on Setting Time and Strength Characteristicsof Cement Mortar, International Journal of Earth Science and Engineering, ISSN 09745904, Volume 09, No. 03

[6] Er. Lalit Kumar, Er. Arvinder Singh, A Study On The Strength Of Concrete Using Crushed Stone Dust as Fine Aggregate, International Journal for Research in Applied Science \& EngineeringTechnology (IJRASET)

[7] IS 10262:2009, 'Concrete Mix Proportioning - Guidelines' First Revision, July 2009

[8] Dr.Sakthivel P B, Ramya C, Raja M, “An Innovative Method of Replacing River Sand by Quarry dust waste in concrete for sustainability",International Journal of Scientific \& Engineering Research, Vol.4, Issue 5,pp.246-249, May 2013.

www.google.com

International Journal of Engineering Research and Applications (IJERA) is UGC approved Journal with Sl. No. 4525, Journal no. 47088. Indexed in Cross Ref, Index Copernicus (ICV 80.82), NASA, Ads, Researcher Id Thomson Reuters, DOAJ.

Priyanka Raj. "Experimental Analysis on Properties of Concrete with Partial Replacement of Cement with Stone Dust." International Journal of Engineering Research and Applications (IJERA) 7.7 (2017): 14-18. 